\title{
Spray characterisation for modelling the tablet coating process
}

\author{
Lars Pasternak $^{* 1}$ and Martin Sommerfeld ${ }^{2}$ \\ 1,2Multiphase Flow Systems, Otto-von-Guericke-University Magdeburg, Halle (Saale) \\ Germany \\ *Corresponding author email : lars.pasternak@ovgu.de
}

\begin{abstract}
In pharmaceutical industry tablets are mostly coated in a rotating drum where the tablet bed continuously moves underneath several spray nozzles which atomise the normally very high viscous coating liquid. In practice unfortunately, the coating is not perfect and tablets may have vacancy defects or coating is not homogeneous (inter-tablet variability). Naturally, also a variation in the coating quality between tables is a problem, called intra-tablet variability. Scientifically well-grounded information on the droplet-tablet collision and spreading is very scarce. Also with respect to numerically predicting such a spray coating process detailed information on this elementary process is needed. Therefore, it is necessary to characterise in the first step the local droplet size and velocity distributions in a spray cross-section by using PDA (phase-Doppler anemometry) measurements. This is required for providing proper spray inlet conditions for spray simulations. At a later stage a model needs to be developed which, depending on the tablet shape, material properties and the collision geometry, can be used to determine the collision outcome during the coating by the atomising nozzle. Through the spray characterisation and the collision modelling, numerical calculations of the whole drum coating system can be performed, with the droplets being regarded as Lagrangian point-particles.
\end{abstract}

\section{Keywords}

Spray coating, spray characterisation, high-viscous liquid atomisation, PDA measurements, droplet-particle collision

\section{Introduction}

The spray coating is a common industrial process to produce granulates or tablets in pharmaceutical industry, where droplets collide with solid particles and the resulting coating or film thickness determines the product properties. For example, the film thickness remarkably influences the dissolving behaviour of tablets. In addition, the coating provides mechanical protection for the API (active pharmaceutical ingredients) and helps to neutralise the taste of the API and ensure colour identification. The coating processes are normally conducted in rotating drums or pans, as well as in fluidised beds (Turton and Cheng 2005). During these processes, heated air flows through the rotating drum or fluidised bed systems, which enables the evaporation of the solvent and enhances drying of the droplets on the solid surface to generate a homogenous film. An uniform film thickness increases the cosmetic appearance of the final product, too. This factor is depending on the customer country and may be a less important or a critical parameter in other countries (e.g. Japan).

The coating of tablets is typically done in a rotating drum without fluidisation of the tablet bed, but a flow of heated air through the moving tablet bed. To describe this process, the simultaneous heat and mass transfer, the interaction between the tablets and the spray and the contact of neighbouring tablets needs to be taken into account. In addition, the tablets generally have a non-spherical shape, like for example round, oval, bullet or almond. Due to the non-spherical shape, the tablets can have different orientation with respect to the spraying system, or droplet trajectories, which could cause a non-uniform coating. In order to describe the full coating process numerically, a hybrid approach needs to be developed which includes 
the different sub-scale elementary processes. The flow of the drying air and the droplet transport inside the spray can be simulated with the Euler/Lagrange approach, where the droplets are regarded as Lagrangian point-particles. Normally one computational point-particle represents a certain number of real droplets, called parcel concept (Sommerfeld 2017). Therefore, models are required to describe all relevant droplet-scale processes, such as the collision outcome of the inter-droplet collisions inside the spray (see e.g. Sommerfeld and Kuschel 2016 and Sommerfeld and Pasternak 2019) or the impact of droplets on solid walls (Pasternak et al. 2021). In the case of a moving tablet bed the Euler/Lagrange spray simulations needs to be coupled with a Discrete-Element-Method (DEM). With such spray computations and the simulation of the tablet motion in the coater, the coating outcome can be calculated by using models based on single droplet-particle collisions (e.g. Pasternak et al. 2021). For taking into account the complex spray pattern produced by applied sophisticated two-fluid nozzles the inlet conditions for the sprays entering the computational domain need to be obtained experimentally, for example by a phase-Doppler anemometer (PDA), which provides local droplet size distributions as well as the size-velocity correlations for all three components. These measurements for high-viscous coating liquids are the subject of the present contribution.

\section{Experimental setup}

To develop a model for the tablet coating process, detailed experimental studies are required. Therefore, an experimental setup (see Fig. 1 left) was developed, which allows the microscopic analysis of the droplet properties inside the spray as well as the analysis of the spray droplet collisions on the surface of a moving tablet bed.

For this purpose, the designed test facility allows the transport of single or several tablets linearly through a droplet chain or a two-fluid atomisation nozzle with velocities up to $0.35 \mathrm{~m} / \mathrm{s}$. This transport could be realised for multiple coatings, while moving forward and backwards with predefined delay times for intermediate drying. To visualise the coating process, a Photron SA4 high-speed camera records the colliding droplets with an exposure time of $1 \mu \mathrm{s}$. To achieve this exposure time and compensate the larger f-number of the telecentric lens, a high power LED Luminus CBT-90 is used for backlighting. The oscillating single droplet generator is able to operate up to $80 \mathrm{mPas}$ with a droplet size range of $300 \mu \mathrm{m}$ to $600 \mu \mathrm{m}$, which however is not a relevant part for this actual study.

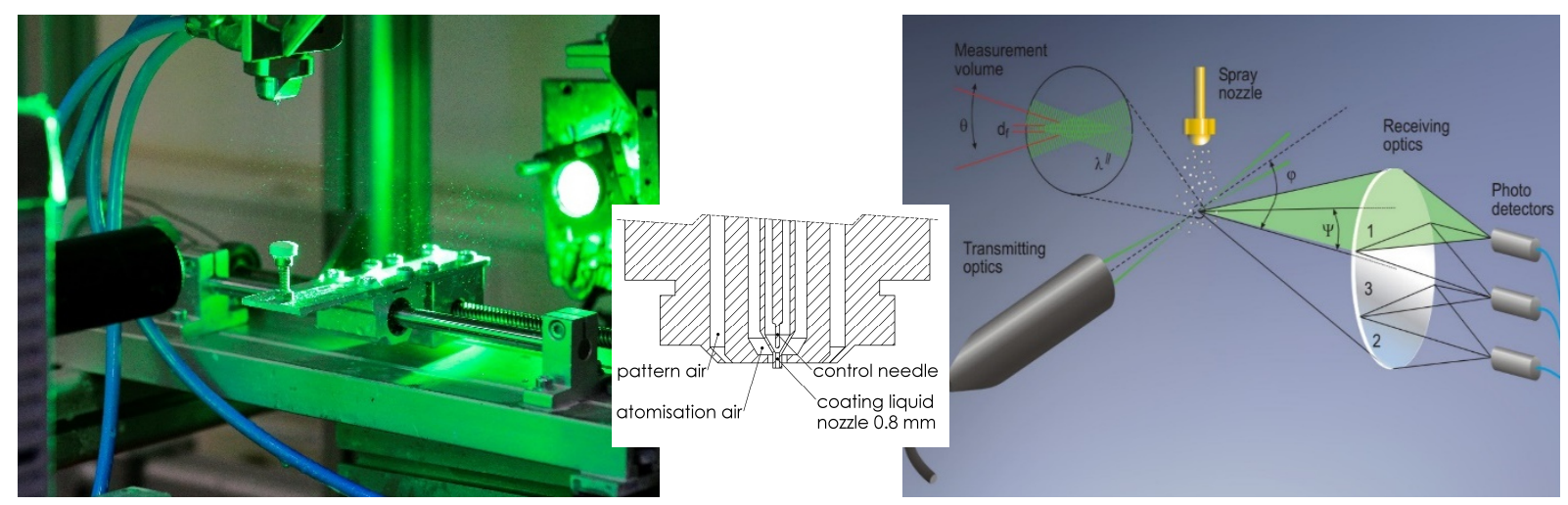

Fig. 1 left: Experimental imaging setup with linear tablet transport system, pneumatic atomizing nozzle, shadow imaging high-speed camera system with single high-power LED; middle: Schematic diagram of the two phase atomization nozzle; right: Schematic diagram of the PDA setup for spray characterization (Dantec 2019). 
For characterising the spray, produced by the two-fluid atomisation nozzle (type: Schlick 970 S75 ABC, $0.8 \mathrm{~mm}$ nozzle), the high-speed camera system was replaced by a 2D PDA system from Dantec (see Fig. 1 right). This allows a detailed determination of the local droplet size and velocity distributions inside the elliptical spray cone at a small distance underneath the spray exit (here about $50 \mathrm{~mm}$ ) where liquid jet break-up is already completed. Such results are essential data to define the inlet conditions for the numerical Euler/Lagrange spray simulations. The PDA is operated with a $310 \mathrm{~mm}$ transmitter lens, which provides a measurement volume of $0.15 \times 2.34 \mathrm{~mm}$. The large aperture type $A$ was used in the receiver (401.5 mm lens) to detect droplets $>0.6 \mu \mathrm{m}$ up to $87 \mu \mathrm{m}$ with the Dantec BSA3 and a scattering angle of $30^{\circ}$. The measuring time was limited to $30 \mathrm{~s}$ or stopped after reaching 25,000 samples. Because of the wide range of the axial velocity distribution, the velocity range in axial direction is $99.89 \mathrm{~m} / \mathrm{s}$ with the centre at $49.95 \mathrm{~m} / \mathrm{s}$ and the span in radial direction $31.21 \mathrm{~m} / \mathrm{s}$ with a variable centre, related to the position.

\section{Coating material characterisation}

Since the coating material in pharmaceutical industry is a combination of a water solvable polymer, mixed with nanoparticles as pigments and larger particles for lubrication (see Fig. 2), the correlation between the coating liquid properties and the solid content in the dispersion had to be investigated. For measuring the static liquid properties the experiments are performed at $23{ }^{\circ} \mathrm{C}$ with distilled water as solvent. The measurements of the density are carried out by using a $50 \mathrm{ml}$ pycnometer, for the viscosity determination an Ubbelohde (II and III) and falling ball viscometer (2 ball sizes) was used and the surface tension was obtained with a ring tensiometer. Since the viscosity measurements were performed with static conditions, a potential shear effect on the viscosity could not be determined with the available equipment.

The properties of the dispersions with different mass concentrations are shown in Fig. 3. For the applied coating liquid the standard mass concentration is $14.3 \mathrm{Ma} \%$. This concentration of the coating powder, Opadry ${ }^{\circledR}$ II from Colorcon, is used in pharmaceutical industry as operating value. As a film former, HPMC is the main content of the Opadry ${ }^{\circledR}$ II dispersion. Because of the resulting high standard viscosity of $232 \mathrm{mPas}$ and the limitations of the maximum liquid viscosity $(80 \mathrm{mPas})$ in the single droplet experiments, three lower concentrations are also analysed. Nevertheless, the results in Fig. 3 indicate a linear trend for the density, viscosity (without taking shear effects into account) and surface tension.

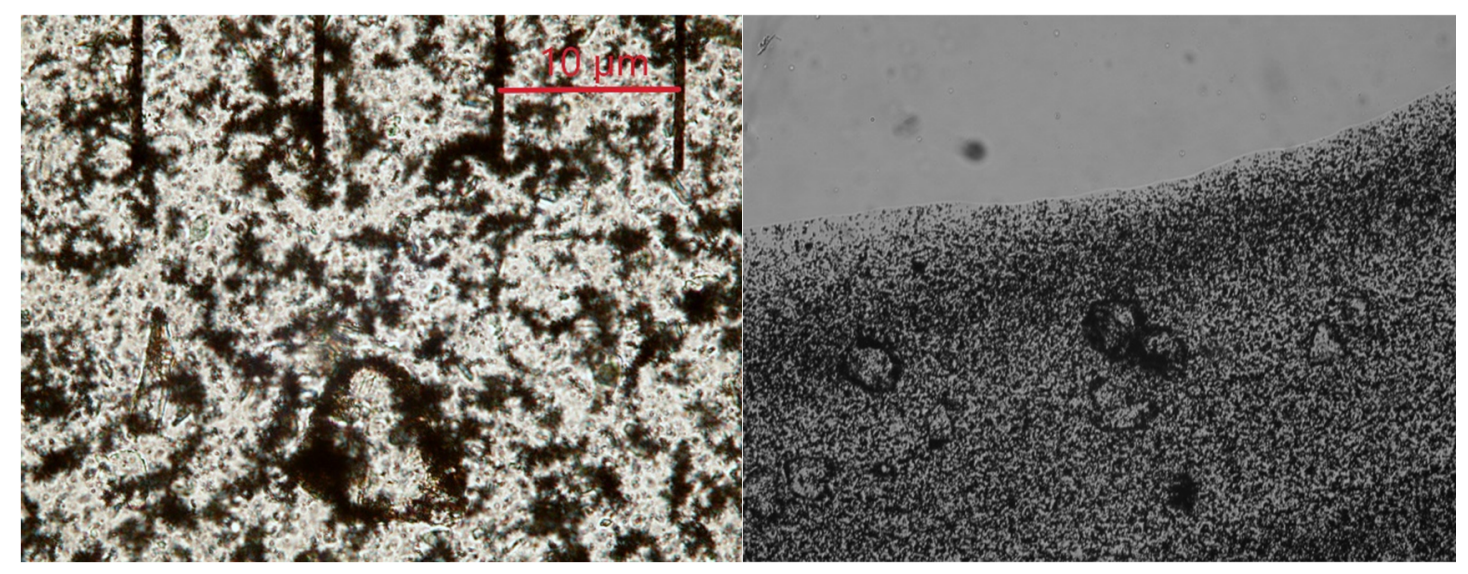

Fig. 2: Microscope images of the coating dispersion (Opadry 14.3 Ma\%) (left), nanoparticles: titanium dioxide and larger particles: talc as lubricant (right). 

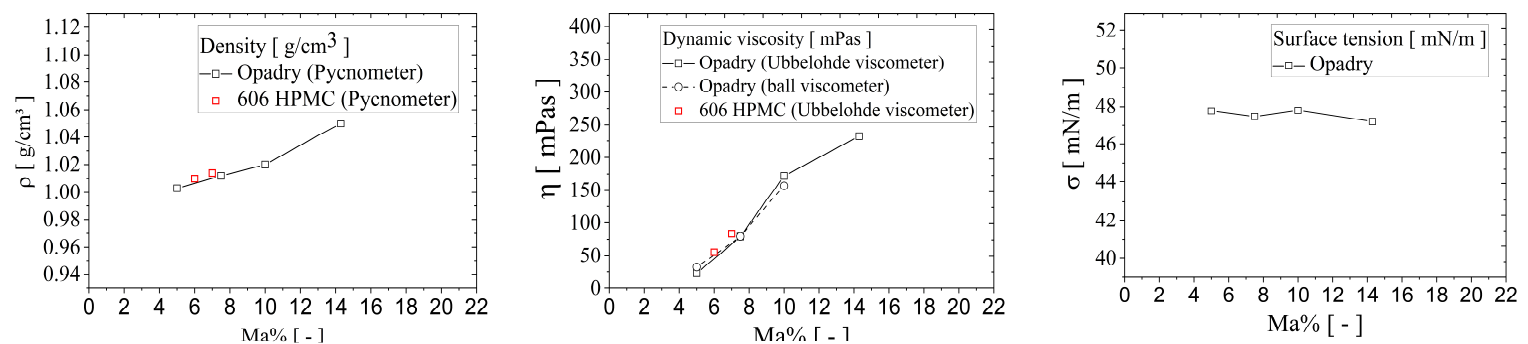

Fig. 3 left: Density mass concentration correlation; middle: Dynamic viscosity mass concentration correlation; right: Surface tension mass concentration correlation.

Due to the high solid particle content (see Fig. 3), the viscosity measurements with the ball viscometer could not be performed for the $14.3 \mathrm{Ma} \%$, as the ball got stuck by particles sticking on the glass wall.

\section{Results and Discussion}

In order to understand the behavior of the spray from the two-fluid nozzle, measurements with different liquids and coating material concentration were performed by using PDA and imaging technique. In Table 1 the considered liquid type, the flow rate and the measurement conditions for the 7 considered cases are summarized. The flow rate is selected according to the conditions applied for laboratory drums in pharmaceutical industry operated with $10-20$ $\mathrm{ml} / \mathrm{min}$. Similar to the flow rate, the atomisation air with 1 bar and pattern air with $0.8 \mathrm{bar}$ (compare to Fig. 1 middle:) are chosen according to the pharmaceutical laboratory tests. Due to the particles inside the coating material, pure HPMC is used to determine the effect of the seeded particles in the coating material. Due to the unknown composition of the Opadry coating material, the used pure HPMC was identified, after the measuring the liquid properties, as polymer with higher molecular weight than the HPMC in the original Opadry coating powder. To achieve the viscosity of $232 \mathrm{mPas}$, the mass concentration had to be reduced to $0.75 \mathrm{Ma} \%$.

Table 1: Properties of the coating liquids considered in the present study.

\begin{tabular}{|c|c|c|c|c|c|c|c|}
\hline Case & $\begin{array}{l}\text { Coating } \\
\text { formulation }\end{array}$ & $\begin{array}{l}\text { Mass } \\
\text { fraction [\%] }\end{array}$ & $\begin{array}{l}\text { Viscosity } \\
\text { [mPas] }\end{array}$ & $\begin{array}{l}\text { Flow rate } \\
{[\mathrm{ml} / \mathrm{min}]}\end{array}$ & $\begin{array}{l}\text { Measurement } \\
\text { technique }\end{array}$ & $\begin{array}{l}\text { Sample / } \\
\text { frames [-] }\end{array}$ & $\begin{array}{l}\text { Meas. vol. I } \\
\text { resolution }\end{array}$ \\
\hline 1 & Opadry/ $\mathrm{H}_{2} \mathrm{O}$ & 14.3 & 232 & 10 & PDA & 10000 & $0.149 \mathrm{~mm}^{3}$ \\
\hline 2 & Opadry $/ \mathrm{H}_{2} \mathrm{O}$ & 14.3 & 172 & 20 & PDA & 10000 & $0.149 \mathrm{~mm}^{3}$ \\
\hline 3 & Opadry $/ \mathrm{H}_{2} \mathrm{O}$ & 10.0 & 79.1 & 10 & PDA & 10000 & $0.149 \mathrm{~mm}^{3}$ \\
\hline 4 & Opadry $/ \mathrm{H}_{2} \mathrm{O}$ & 5.0 & 22.5 & 10 & PDA & 10000 & $0.149 \mathrm{~mm}^{3}$ \\
\hline 5 & Water & - & 0.9 & 10 & PDA & 10000 & $0.149 \mathrm{~mm}^{3}$ \\
\hline 6 & $\mathrm{HPMC} / \mathrm{H}_{2} \mathrm{O}$ & 0.75 & 235 & 10 & PDA & 10000 & $0.149 \mathrm{~mm}^{3}$ \\
\hline
\end{tabular}

In order to characterise the spray for the conditions summarised in Table1, the local mass flux, the droplet size and velocity distributions were measured at four representative locations summarised in the following figures. The origin is located at the centre of the nozzle orifice and the measurements were performed $50 \mathrm{~mm}$ below the exit at four lateral positions, namely $x=0,10,20$ and $30 \mathrm{~mm}$, in the major expansion direction of the flat fan spray cone. These measuring points are labelled in Fig. 4 as a) - d), each considering all 7 cases of Table 1 in sequence. 
Since the atomisation and pattern air for the two-fluid nozzle is identical for all the cases, the droplet size distributions for the different cases are the result of the liquid viscosity and flow rate. The droplet number based size distributions in Fig. 4 show a viscosity and liquid type effect, but no observable flow rate influence for the positions 0, 10 and $20 \mathrm{~mm}$ (see Fig. $4 \mathrm{a}$, $b$ and $c$ ) inside the spray. The effect of the flow rate can be identified on the edge of the spray (see Fig. $4 \mathrm{~d}$ ), where the probability of smaller droplets $(<10 \mu \mathrm{m})$ is much lower and for the larger droplets $(>55 \mu \mathrm{m}$ ) higher for the flow rate of $20 \mathrm{ml} / \mathrm{min}$ (Case 2, red circles) compared to the other Opadry liquids. Since the flow rate of $10 \mathrm{ml} / \mathrm{min}$ is close to the minimal design flow rate of $5 \mathrm{~g} / \mathrm{min}$ of the nozzle, a flow rate effect may occur for the other position with flow rates (>>20 $\mathrm{ml} / \mathrm{min}$ ). The plots of the droplet number PDFs show for the cases 1 to 6 the highest probability of droplets with a size $<10 \mu \mathrm{m}$ and towards the spray cone edge an increasing size range to droplets up to $87 \mu \mathrm{m}$ is observed. The high amount of small droplets found in the spray required a PDA setup suitable for small droplet detection down to droplet size of about $1 \mu \mathrm{m}$. For this reason, the upper detection limit is $87 \mu \mathrm{m}$. Nevertheless, the effect of the liquid viscosity is visible for the different Opadry cases (i.e. Cases 1,3 and 4). The Opadry dispersion with $5 \mathrm{Ma} \%$ has a shift to larger droplets compared to the 10 and $14.3 \mathrm{Ma} \%$ in the central spray region 0 and $10 \mathrm{~mm}$ (see Fig. $4 \mathrm{a}$ ) and b)). At $20 \mathrm{~mm}$ lateral position from the nozzle axis, the distributions for the different Opadry liquids are very similar (see Fig. $4 \mathrm{c}$ ), even very similar to pure water. At the edge of the spray cone (see Fig. $4 \mathrm{~d}$ :) the size distribution for the lower viscous Opadry dispersion (Case 4) has no reduced number of small droplets $<5 \mu \mathrm{m}$ like for the other Opadry concentrations. The second peak in the size distribution in Fig. $4 \mathrm{~d}$ : (around $35 \mu \mathrm{m}$ ) is compared to the different Opadry cases for the $5.0 \mathrm{Ma} \%$ spray also higher. The reference liquid water has a comparable profile to the Opadry cases for the position 0,10 and $20 \mathrm{~mm}$, with a shift of about $5 \mu \mathrm{m}$ towards larger droplets. At the spray cone edge, the size distributions of water and pure HPMC are comparable (Fig. $4 \mathrm{~d}$ ). In this region most of the droplets for water and pure HPMC can be located in the range between 25 to $45 \mu \mathrm{m}$, without showing many droplets with $<10 \mu \mathrm{m}$ compared to the Opadry liquids. The size distribution measured for the HPMC (i.e. Case 6 with the same viscosity as the Opadry liquid Case $1 ; 232 \mathrm{mPas}$ ) at the positions 0,10 and $30 \mathrm{~mm}$ show a shift of 10 to $15 \mu \mathrm{m}$ to larger droplets in comparison to the Opadry powder.

Consequently, the HPMC solution yields larger droplets, but with much less variation across the spray (i.e. between 15 and $30 \mu \mathrm{m}$ ), at least for the locations considered. This will of course support a more homogeneous spatial distribution of the droplets in the spray, which naturally should yield a more homogeneous coating of the tablet bed. On the other hand, the Opadry liquid gives very small droplets with less than $10 \mu \mathrm{m}$ in the core region and very broad size distributions at the spray edge. Here it is questionable whether droplets smaller than $10 \mu \mathrm{m}$ are very suitable for tablet coating since the surface tension force is very strong and may cause droplet rebound from the tablet surface. Moreover, it can be concluded that for the Opadry liquid the correlation between the powder concentration (viscosity of the liquid) and the produced droplet size distribution is quite small. 

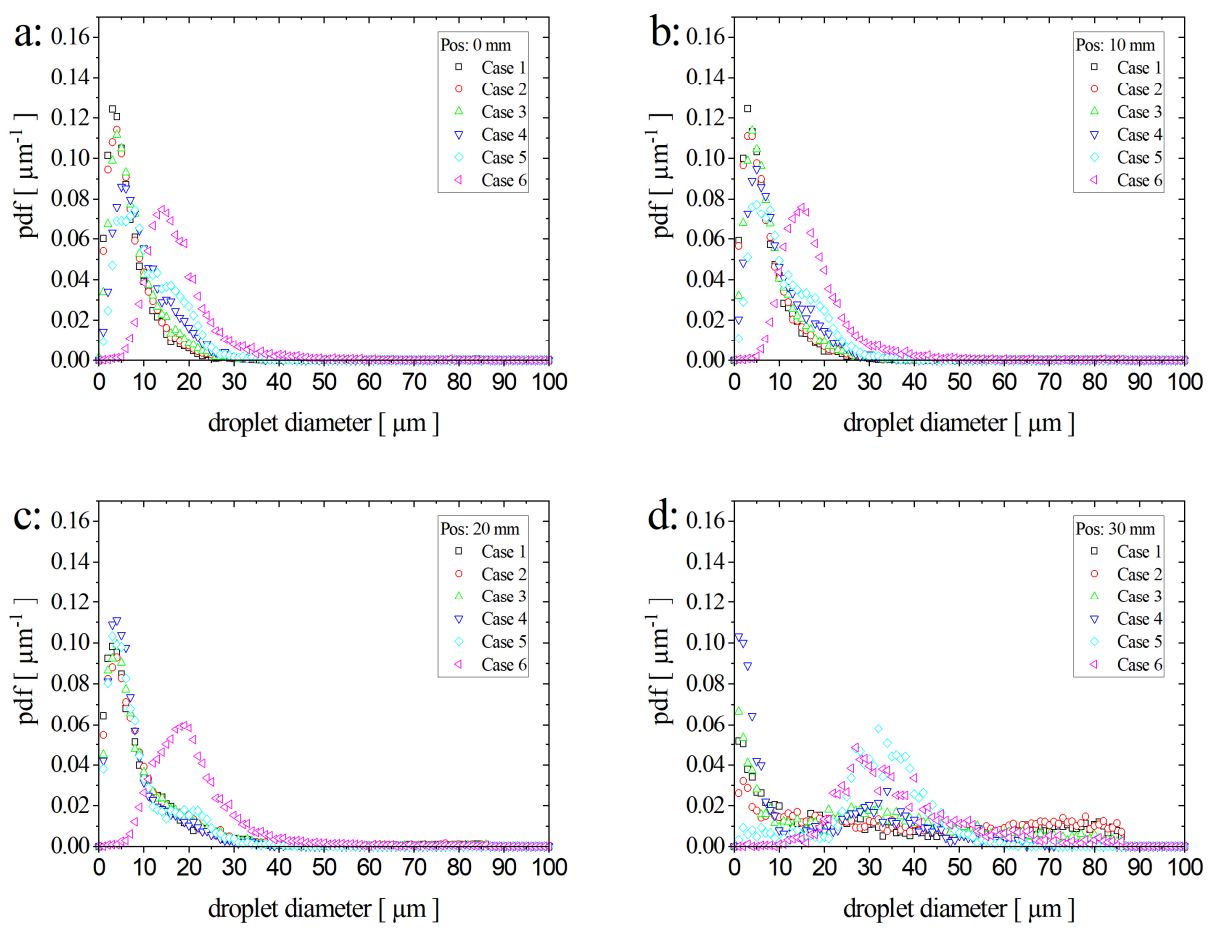

Fig. 4: Probability density functions (PDFs) for the droplet sizes $50 \mathrm{~mm}$ below the nozzle exit, measured for different liquids (see Table 1 ) and measuring points $\mathbf{a}) \mathbf{- d}$.

Due to the appreciable amount of larger droplets or liquid fragments near the edge of the spray cone for Opadry liquid, the effect of these droplets on the coating was also visualised. For that purpose shadow images were taken for a single tablet traversing the edge of the spray (Figure 5 ). In this image series, a large droplet, or better liquid fragment, with a diameter of about $250 \mu \mathrm{m}$ hits the tablet surface. In the initial stage clearly a kind of corona is formed and finally the droplet is completely splashed, whereby only a small liquid fraction forms a film on the tablet surface.
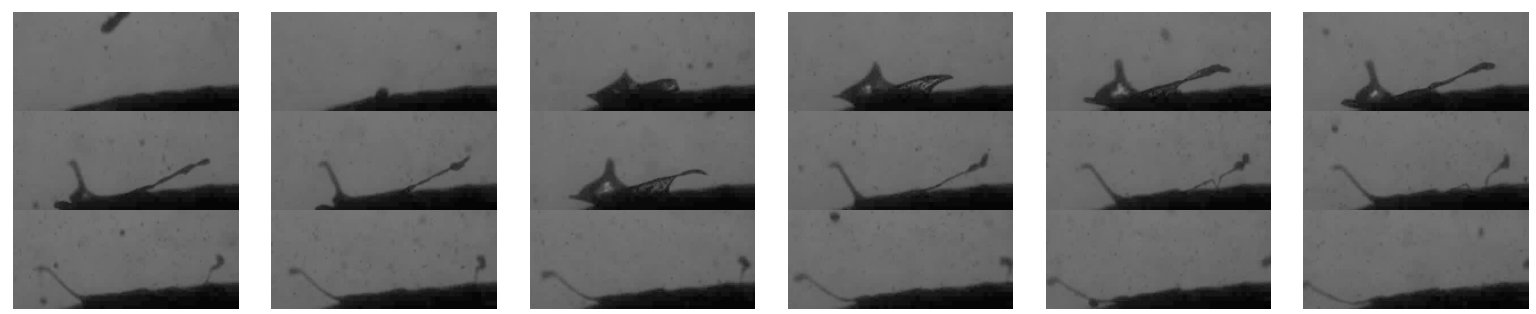

Fig. 5: High resolution image sequence of colliding droplets (big droplet $\sim 250 \mu \mathrm{m}$ ) with a tablet surface during linear transport through the spray, frame interval $/ \Delta t=10 \mu s$.

The droplet velocity in axial direction is plotted in Fig. 6 a) to d), again for the cases 1 to 5 (Table 1) and the same lateral positions as before. In the core region the axial velocity distributions are normal distributed and very similar for all conditions (Table 1); only the HPMC gives slightly higher velocities. The droplet mean velocities in the spray center (i.e. $0 \mathrm{~mm}$ and $10 \mathrm{~mm}$ ) have quite high values of between $40 \mathrm{~m} / \mathrm{s}$ and $35 \mathrm{~m} / \mathrm{s}$. Towards the spray cone edge (i.e. $20 \mathrm{~mm}$ and $30 \mathrm{~mm}$ ), the mean axial velocity is expectedly decreasing and showing a 
truncated normal distribution with a maximum around zero velocity. Again the HPMC gives different distributions with higher velocities.

The radial velocity PDFs (i.e. in the direction of the flat pattern spray) presented in Figure 7 again for the different cases (Table 1) and the different lateral locations indicate that the spray is not fully symmetric. For a fully symmetric spray with respect to the coordinate system, the mean radial velocity on the nozzle axis should be zero. This condition is found for the PDFs measured at $10 \mathrm{~mm}$ from the spray axis, indicating a spray offset which may be caused by the pattern air. Nevertheless, at all lateral positions the different liquids (Case 1 to 6 ) show very similar radial velocity distributions. Additional measurements by PDA to the other side of the spray are necessary in order to confirm the offset, which of course should be properly considered in a Euler/Lagrange simulation.
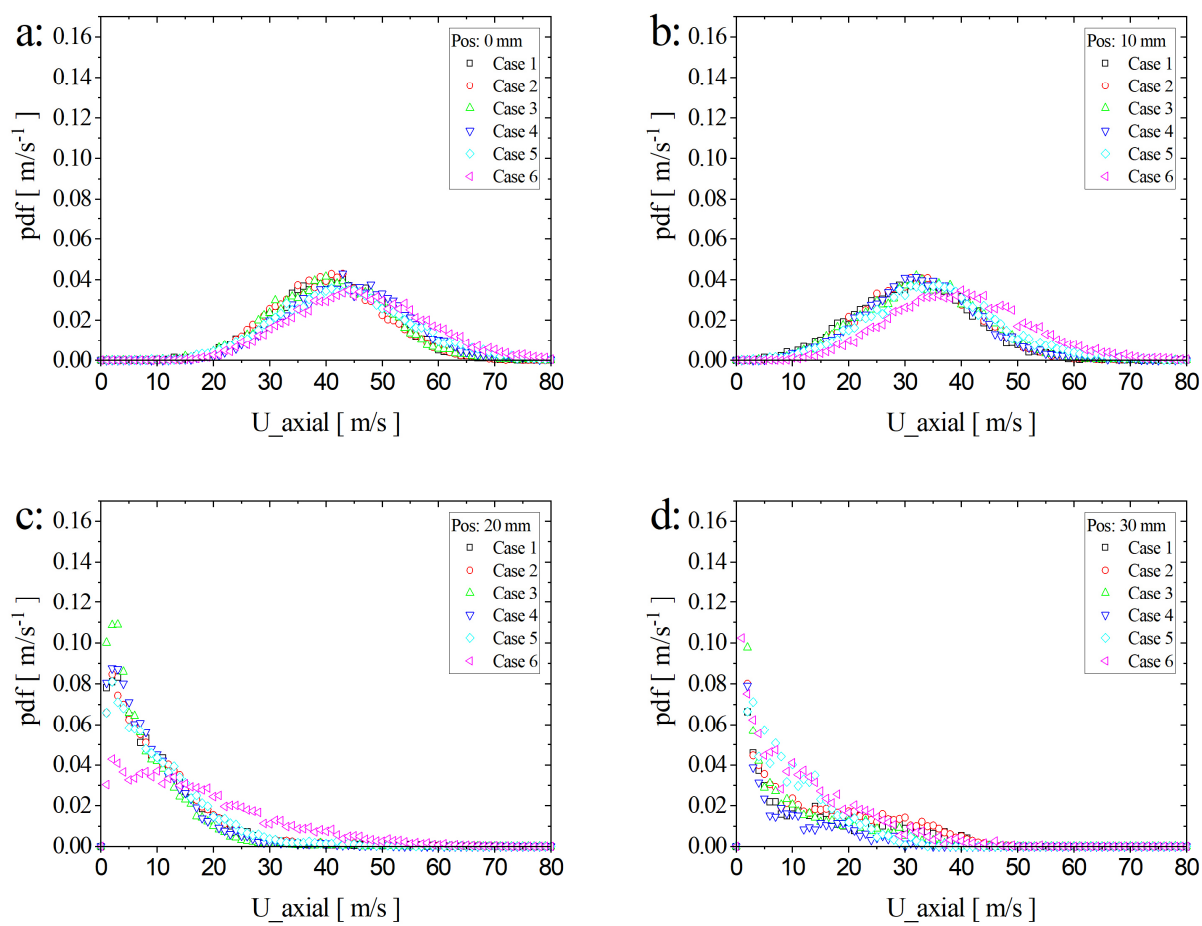

Fig. 6: Probability density functions (PDFs) for the droplet axial velocity in flow direction 50 $\mathrm{mm}$ below the nozzle exit, measured for different liquids (see Table 1 ) and measuring points a: - d: (y= 0, 10, $2030 \mathrm{~mm})$. 

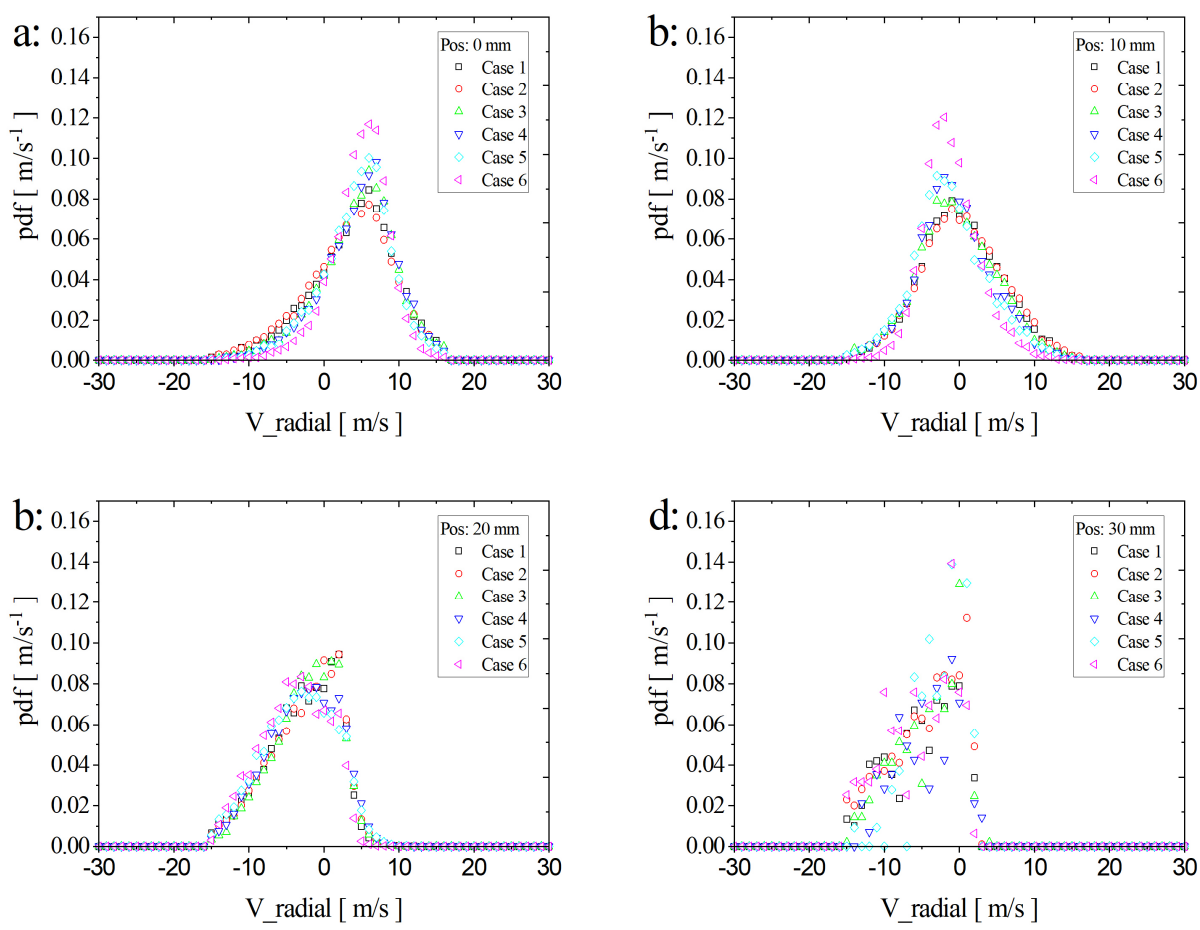

Fig. 7: Probability density functions (PDFs) for the droplet radial velocity in expansion direction of the flat pattern spray cone $50 \mathrm{~mm}$ below the nozzle exit, measured for different liquids (see Table 1) and measuring points $a:-d:(y=0,10,2030 \mathrm{~mm})$.

Essential for specifying the spray inlet conditions in Euler/Lagrange computations are the correlations between droplet size and velocity. These measured correlations are shown in Fig. 8 for the axial velocity component including both the mean and RMS axial velocities. The cases considered are the standard Opadry liquid with $14.3 \mathrm{Ma} \%$ and a flow rate of 10 and 20 $\mathrm{ml} / \mathrm{min}$ (Case 1 and 2) as well as distilled water with $10 \mathrm{ml} / \mathrm{min}$ (Case 5). Expectedly, the mean axial velocities are increasing with the droplet diameter up to about $60 \mu \mathrm{m}$. For droplets larger than $60 \mu \mathrm{m}$ the mean velocity remains almost constant (Fig. 8 a: to c:) or even decreases (see Fig. $8 \mathrm{~d}$ :). A dependence of the profiles on the flow rate is not visible for the two Opadry cases 1 and 2. However, a remarkable difference is seen between Opadry and water. The mean axial water droplet velocities are higher in the range of 10 to $50 \mu \mathrm{m}$ in the core of the spray compared to the Opadry dispersions. The size detection limitation yields a loss of data for the droplets $>87 \mu \mathrm{m}$ in the Opadry sprays. This limitation of the droplet size detection does not occur for the water experiments, since the droplets in the water spray never reach these large sizes. For the positions 0 and $10 \mathrm{~mm}$, the largest detected water droplets are in the range of $45-55 \mu \mathrm{m}$ and at the spray cone edge the water droplet size increased up to $70 \mu \mathrm{m}$. The droplet size related RMS velocities show an approximate linear trend, with a marginal slope to higher mean RMS velocities.

It should be taken into account that the droplet number sampled in each size class is decreasing for growing droplet sizes. Therefore, the correlation results for the larger size classes are statistically less accurate. 

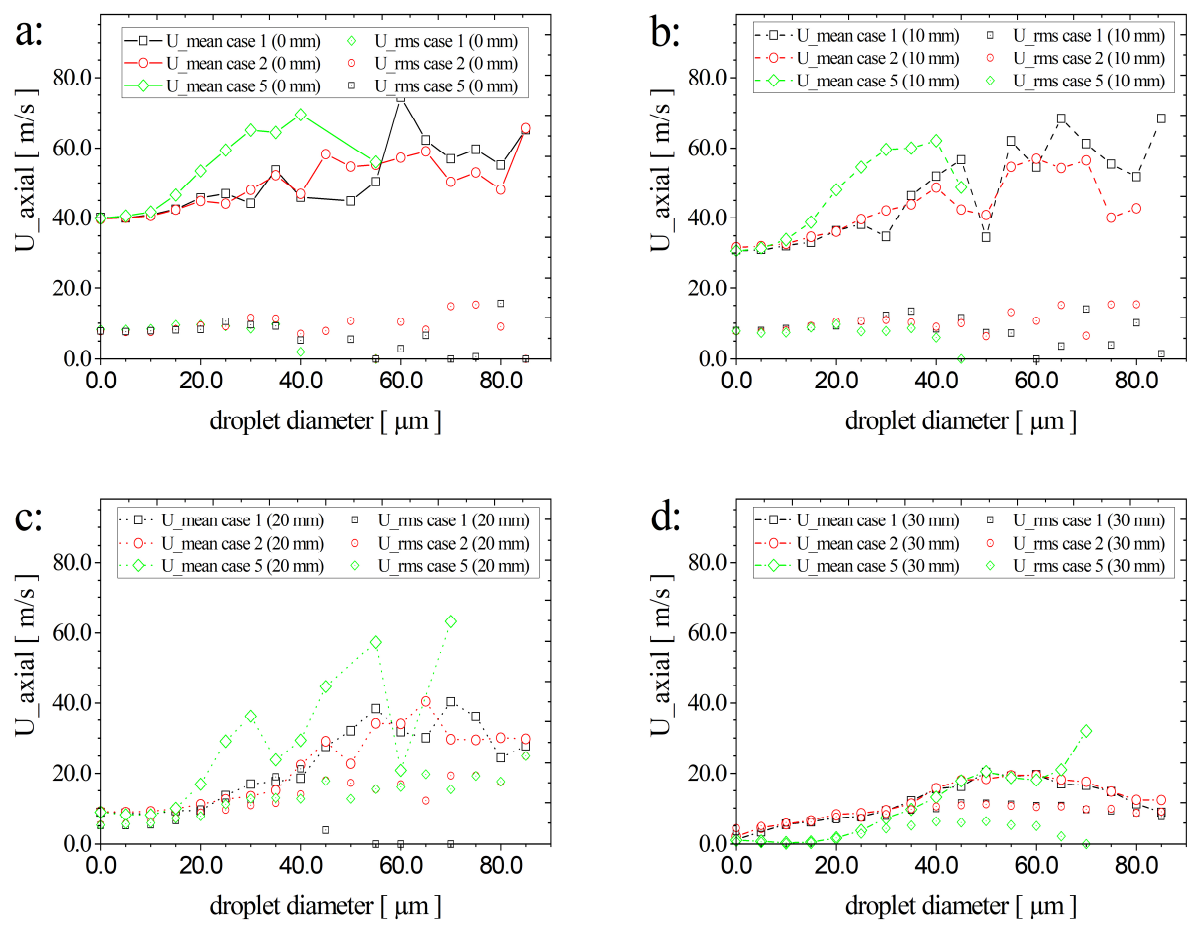

Fig. 8: Droplet size and axial velocity correlation in flow direction (mean and RMS components) $50 \mathrm{~mm}$ below the nozzle exit, case 1, 2 and 5 (see Table 1) and measuring points a: - $d:(y=0,10,2030 \mathrm{~mm})$.

In addition to the droplet size and velocity distributions, the local mass flux has to be provided to simulate the spray injection by a Lagrangian approach. The calculation of the local mass flux in the axial direction is based on the cross-section of the laser beams in the measuring volume. The mass flux profiles in dependence of droplet size show for all cases (see Table 1) very similar shapes (Fig. 9). In the core region of the spray the mass flux shows a maximum value near the highest probable droplet diameter and at the edge the largest mass flux is found for the largest droplets which of course carry a large mass, but their number is small. There seems to be a viscosity effect on the mass flux profiles with the trend that a reduced viscosity gives higher local mass flux (clearly seen in Figure $9 \mathrm{~b}$ ). Similar to the shift of the droplet size distribution to larger values (Fig. 4) for the HPMC liquid, also the mass flux profiles are clearly shifted to larger droplets. Expectedly, the increase in flow rate for the Opadry liquid (compare Case 1 and 2), yields also an upwards shift of the mass flux profiles, most pronounce for the results at lateral positions of $10 \mathrm{~mm}$ (Fig. $9 \mathrm{~b}$ ) and $30 \mathrm{~mm}$ (Fig. $9 \mathrm{~d}$ ). 

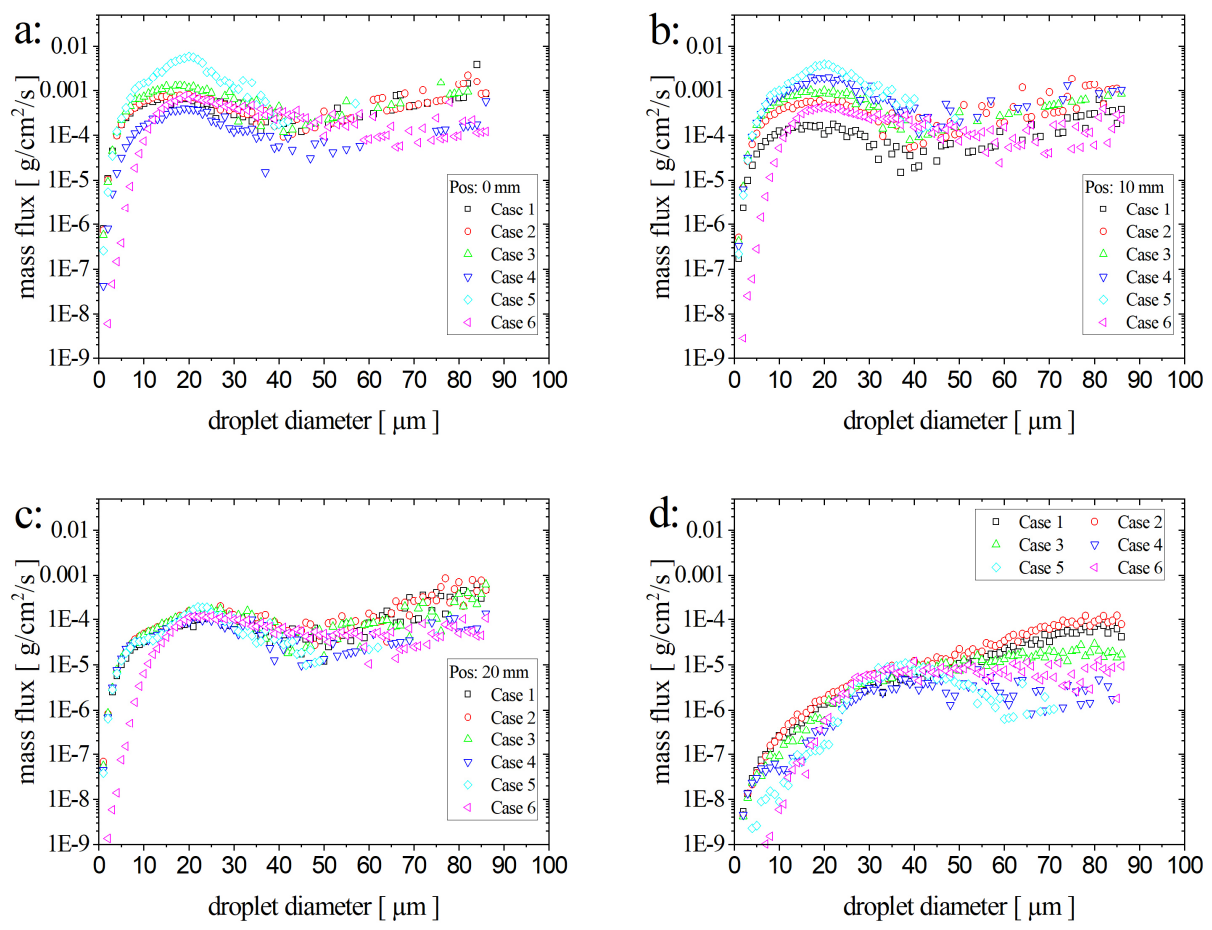

Fig. 9: Droplet size and mass flux correlation in flow direction $50 \mathrm{~mm}$ below the nozzle exit, measured for different liquids (see Table 1) and measuring points a: - $\mathbf{d}$ : $(\mathbf{y}=\mathbf{0}, \mathbf{1 0}, 2030$ $\mathrm{mm})$.

\section{Conclusions}

For allowing numerical simulations of tablet coating in a rotating drum by the Euler/Lagrange approach the spray injection has to be described through detailed measurements of droplet size, velocity and mass flux, since at the moment the used complex atomisers do not allow for a simple injection model. For efficiently doing such measurements a PDA was applied for obtaining the spray inlet profiles. In the present studies first the influence of liquid flow rate and the type of coating liquid (i.e. liquid viscosity) on the resulting spray properties was analysed. Essential for describing the tablet coating process is of course the produced droplet size and the mass flux. In the present industrial process the high viscous Opadry system with 14.3 Ma\% is applied. With the present nozzle system and flow rates Opadry liquid yielded a very inhomogeneous distribution of droplet sizes in the spray; in the core region the mean droplet diameter was found to be below $10 \mu \mathrm{m}$ and at the spray edge the droplet sizes were distributed over the entire measurable size spectrum up to $87 \mu \mathrm{m}$. Such a condition is not very much suitable for tablet coating since very small droplets may not deposit on the tablet and large droplets yield strong splashing.

Alternatively the spray properties for a pure HPMC polymer, atomised under the same operational conditions, were measured by the PDA system. For the same liquid viscosity this coating liquid yielded an almost constant droplet mean diameter between 20 to $30 \mu \mathrm{m}$ across the entire spray. Such a droplet size is much more suitable to realise an efficient tablet coating.

\section{Acknowledgments}

The financial support of the present studies by the Bayerische Forschungsstiftung (BFS) under contract number AZ-1371-19 is gratefully acknowledged. 


\section{References}

Pasternak, L., Moreno Manas, M.J., Sommerfeld, M., 2020. Influence of droplet properties on the coating of free-falling spherical particles. Atomization and Sprays, 31(2):37-61 (2021)

Sommerfeld, M. and Kuschel, M.: Modelling droplet collision outcomes for different substances and viscosities. Experiments in Fluids, Vol. 57, 187 (2016)

Sommerfeld, M.: Numerical methods for dispersed multiphase flows. In: Particles in Flows (Eds. T. Bodnár, G.P. Galdi, Š. Necčasová), Series Advances in Mathematical Fluid Mechanics, Springer International Publishing, 327 - 396 (2017), ISBN 978-3-319-60281-3

Sommerfeld, M., and Pasternak, L.: Advances in Modelling of Binary Droplet Collision Outcomes in Sprays: A Review of Available Knowledge. Int. J. Multiphase Flow, Vol. 117, pp. 182-205 (2019)

Turton, R. and Cheng, X.X.: The sale-up of spray coating processes for granular solids and tablets. Powder Technology, Vol. 150, 78-85 (2005) 